\title{
Making Makerspaces Work
}

\section{for Everyone}

\section{Lessons in Accessibility}

\author{
BARBARA KLIPPER
}

A $\mathrm{n}$ article in the March 10, 2014, issue of People magazine tells the story of a seventeen-year-old boy who used the 3-D printer at his local library to make a prosthetic hand for Matthew Shields, a nine-year-old family friend born without fingers on his right hand. The story is awesome and heartwarming and way beyond what most librarians think of when they introduce this technology.

I loved the article, and it got me thinking ... with or without a prosthetic hand, would someone like Matthew be able to use the 3-D printer? What if he had a cognitive impairment or autism instead of a physical disability? I would guess that few librarians who are now providing 3-D printers or offering makerspaces are asking those questions and making sure that the answers are "yes."

Makerspaces are all the rage in the library world. They are a wonderful way to introduce new technologies and to provide new outlets for creativity, learning, and community engagement. But they are not for everyone, though they can be if accessibility becomes one of the considerations when designing makerspaces and maker programs or when introducing technologies like 3-D printing.
When librarians think about accessibility, what usually comes to mind is a person using a wheelchair who needs a ramp to reach the library door, but that's a limited view. I once participated in a disability awareness workshop called "It Takes More than a Ramp," and this has never been truer than in this age of advanced technology.

Accessible "making" at the library can enrich the lives of people with disabilities in many ways, allowing them to create items to improve their world, have fun, and identify hobby and career possibilities.

The public library in Washington, D.C., for example, has offered accessible maker programming. In 2013, four students, supervised by assistant professor Mega M. Subramaniam from the University of Maryland, collaborated with a team from FutureMakers (kidsmakethingsbetter.com) on an event for individuals with cognitive disabilities and visual impairments at a library branch.

They made flying machines from craft materials and tracks for a marble run. The enthusiastic student organizers have even written a guide for librarians who want to offer similar maker

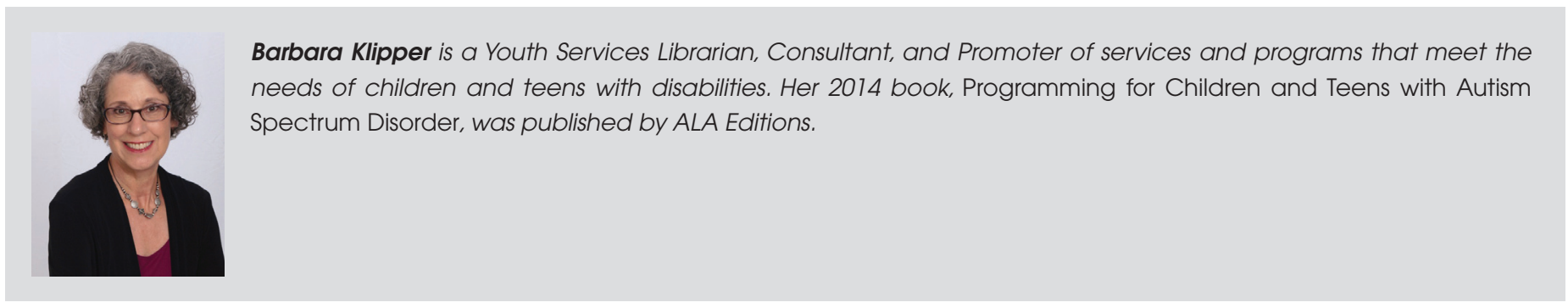


projects. Brooklyn Public Library has also entered the arena, introducing accessible robotics, computer-assisted graphic novel design, and LEGO programming.

If you want to follow their lead and offer maker programs for children with disabilities and their families, there are resources available. One is DIYAbility, which is at the forefront of bringing the maker movement to people with disabilities. Cofounded by John Schimmel, a technologist who teaches at New York University, and Holly Cohen, an occupational therapist, DIYAbility offers workshops-for example a summer making session for teens with physical disabilities and their siblings, and a Toy Hacking Kit, which contains the items needed to hack a toy and create an ability switch. Instructions for adapting toys can also be found on their website (diyability.org). Their work can form the basis of a great library program.

Another name to know is Amy Hurst, assistant professor of human-computer interaction at the University of Maryland, Baltimore County. She asserts that people with disabilities are more likely to use assistive technology devices they make or modify themselves, and shares resources like www.workshopsolutions.com, which offers DIY assistive technology project ideas, including some for objects to be used by children. ${ }^{1}$ Why not make them at the library?
Maker projects for children with disabilities and their families shouldn't just focus on adaptive technology. Kids with disabilities, like all kids, can enjoy and learn from simply using 3-D printers and may very much want to join in the robotics and other maker programs you already offer. You may be surprised to find that you need nothing more than instructions in multiple formats and additional adult helpers to make those accessible and inclusive.

Ask the children with disabilities in your community and their parents what is needed for them to participate. It may take a little time and ingenuity to see how things can be tweaked, but it will be worth it. After all, think about what the Matthew Shieldses of the world will be able to accomplish with the help, not only of a talented neighbor, but also of a friendly and accessibility-conscious librarian. \&

\section{References}

1. Amy Hurst and Jasmine Tobias, "Empowering Individuals with Do-It-Yourself Assistive Technology," in Assets '11, the proceedings of the 13th international ACM SIGACCESS Conference on Computers and Accessibility, 2011, accessed April 28, 2014, https://s3.amazonaws.com/www.amyhurst .com/publications/assets-2011-hurst-DIYAT.pdf, 11-18.

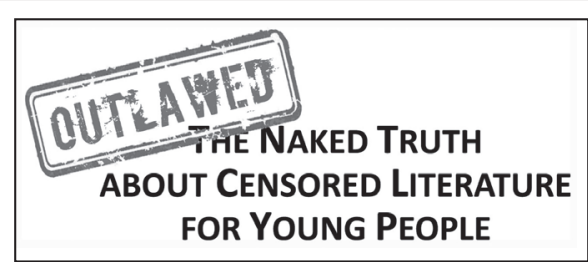

\section{- CALL FOR PROPOSALS •}

Arne Nixon Center for the Study of Children's Literature, Madden Library, Fresno State April 10-12, 2015. www.outlawed2015.com

- Censorship provokes many who believe that children and adolescents benefit from considering diverse viewpoints and cultural experiences. In recent years many examples of literature for young people have been challenged in schools and libraries. This conference will explore how censorship affects young readers in a world where controversial issues of identity circulate more freely than ever. - Conference host is the Arne Nixon Center at Fresno State (see www.arnenixon center.org), a collection with an international and multicultural emphasis, with one of the largest U.S. collections of LGBT+ literature for children and young adults. - Scholars, librarians, teachers, writers, and illustrators are invited to submit proposals for 15-20 min. presentations, roundtable discussions, and workshops that may highlight creative work, community engagement, pedagogy, or scholarship; limit proposals to $250-300$ words. An entire session is 75 min.; submit 500 words max. Include very brief bios for participants. Indicate AV needs.

- Possible topics include, but are not limited to - Suppressed or silenced histories

- International contexts for censorship - Technology and/or digital literacies $\boldsymbol{\|}$ The use of social media to intervene when books are challenged $-\mathrm{LGBT}+$ literature - Multiculturalism and diversity " Sex and censorship " Self-censorship - Creating curriculum that supports the use of banned books " "Artivism" and subtext in illustrations - Graphic novels, novels in verse, and experimentation with form - Libraries (school/community/archives) and closed reference cases - Publishing or Pre-Censorship - Schools (K-12, public/private) - Religion, spirituality, and

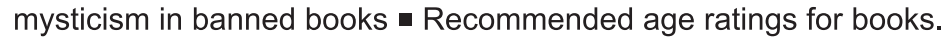

- Submit proposals electronically to Prof. Kathleen Godfrey at kgodfrey@csufresno.edu no later than 26 November 2014. 